\title{
Exploring the application of co-design to transformative service research
}

\begin{abstract}
Purpose

This study investigates in a transformative service research (TSR) context how users can be involved through co-design and what contributions they can make during this process.

\section{Design/methodology/approach}

A six-step co-design process was used to plan and facilitate two co-design sessions that involved a total of 24 participants. The collected data include field notes, transcripts from group discussions, recordings of idea presentations, and the evaluation of ideas.
\end{abstract}

\section{Findings}

A recruitment strategy which utilizes strong networks and sensitizes users through generating awareness of the underlying issue can prevent the waste of valuable resources. During the facilitation stage, experts need to find the fine line between close guidance and giving voice to the users. User-generated ideas set the starting point for new value propositions that more effectively support users in their value creation processes.

\section{Research limitations/implications:}

The findings are limited to one specific sample and design task. Future research is required that investigates the application of co-design to other TSR contexts.

\section{Practical implications}

In TSR, organizations will need to follow a different co-design approach owing to the sensitive nature of the design task and/or users that are not driven by innovation-related motivations. Organisations should tap into their networks to raise awareness and recruit suitable participants. To capture users' unique insights and foster the collective creativity, facilitation should focus on enabling participants through the use of design tools and team management.

\section{Originality/value}

The study contributes new insights into requirements, challenges, and benefits of applying codesign to TSR contexts. The study shows that ordinary users, if empowered, can give important insights into the design of new value propositions.

Key words: co-design, transformative service research, service innovation, alcohol education 


\section{Introduction}

Adolescent alcohol consumption and its associated problems is an ongoing concern in the Western society (Hogan et al., 2014). To illustrate, the Australian National Prevention Health Agency (2014) reported that in Australia one third of 12 to 17 year-olds have tried alcohol, and a quarter of adolescents' alcohol consumption levels exceed the recommended guidelines set for adults. Alcohol education has evolved to a central topic in transformative service research (TSR), which focuses on creating uplifting changes and improvements in the well-being of both individuals and society (Anderson et al., 2013). Specifically, from a TSR lens, alcohol education has the potential to improve the well-being of those involved (e.g., improved mental and physical health of adolescents) and the community at large (e.g., decreased financial burden on society due to the associated health problems) (e.g. Mulcahy et al., 2015, RussellBennett et al., 2016, Yam et al., 2017).

Parents play a key role in influencing adolescent attitudes towards alcohol consumption (Newton et al., 2017). This led to the development of alcohol education programs that specifically aimed at improving parenting practices and open communication with adolescent on alcohol-related topics (Williams et al., 2015, Rossow et al., 2016). Yet, only limited success has been reported in regards to improvements of parenting practices, which has been largely ascribed to the lacking participation and engagement in these programs (Toumbourou et al., 2013, Perry et al., 2002). Here it should be noted however, that the majority of these programs are expert-driven in their design (e.g. designed by researchers, public sector workers or social marketers) with limited or no involvement of end users (Dietrich et al., 2016). In fact, an

extensive desk research resulted in the identification of only one program that used a community-based research method (i.e., interviews and focus groups) as part of the program development (Williams et al., 2015). 
The predominant expert-driven approach is somewhat peculiar, since previous service research highlights the difficulties in understanding the specific circumstances surrounding the users' value creation processes (e.g. Gustafsson et al., 2012, Witell et al., 2011). It is only by actively involving customers or users in the innovation process, that organizations can effectively tap in to users' unique knowledge on usage and needs (Trischler et al., 2018b). Despite this, user input is still most often sought from a distance because organizations lack a clear understanding on how users can be involved as active and equal contributors during the innovation process (Jaakkola et al., 2017).

One alternative to expert-driven approaches is co-design. Co-design allows selected users to "become part of the design team as experts of their experiences" (Sanders and Stappers, 2008, p. 12). In this way, users can provide important insights into their latent needs and actively contribute to the development of new ideas for future programs (Dietrich et al., 2017). While co-design has been suggested as key to service design success (Steen et al., 2011, Trischler et al., 2018b), it remains unclear how its process can be planned and facilitated in a TSR context. This is because, in contrast to conventional co-design applications, where users can be selfselected (e.g. Trischler et al., 2018a), in TSR relevant users might not perceive themselves as suitable candidates for co-design, or even be reluctant to participate (Engström and Elg, 2015). This might particularly be true for sensible or nonengaging topics which are central to TSR, such as alcohol education, violence, inequality, and poverty (Rosenbaum, 2015). It points towards specific requirements and consequences that need to be considered in the application of co-design to TSR contexts; an area which, to date however, gained limited attention in the literature (Anderson and Ostrom, 2015).

Against this backdrop, the present article offers an in-depth investigation of co-design applied to a TSR context. This investigation is underpinned by the following research question: 
RQ1: How can ordinary users be actively involved in the co-design of transformative services, specifically those which address sensitive topics?

To address the research question, this study applies a co-design framework, consisting of the six stages resourcing, planning, recruiting, sensitizing, facilitation, and evaluation (Dietrich et al., 2017), to two co-design sessions focusing on developing an alcohol education program for parents. The application of this framework enables the identification of specific factors along each of the six stages that possibly could make the difference between co-design success and failure. The focus is on the involvement of parents who can be classified as ordinary users because they are not typically equipped with technical skills or a detailed knowledge of the underlying service (Magnusson et al., 2016).

In addition, this article investigates the co-design outcomes, specifically in terms of differences between user-generated ideas and the existing expert-driven designs. There is a consensus within the user involvement literature that user-generated ideas are higher in user benefit and originality than the ones developed by experts (e.g. Magnusson et al., 2003, Kristensson et al., 2004, Poetz and Schreier, 2012). Yet, little insights are available on what it is that makes a user-generated idea more innovative and valuable to users. The second research question explores how users can contribute to this process:

RQ2: How do user-driven design ideas differ from expert-driven designs?

To address the second research question, this study compares the ideas generated by users during the co-design activity with existing expert-driven program designs. Thereby, the focus is on identifying changes in the value proposition that will potentially lead to higher well-being outcomes. Addressing these research questions is important because they generate a more holistic understanding of the key requirements for, and consequences of, actively involving users in service design processes that concern transformative aims. Practitioners obtain 
guidance on the application of co-design as an effective alternative to conventional market research approaches.

\section{Theoretical background}

\section{Transformative service research}

Transformative service research (TSR) concerns services that create change with the aim to improve the well-being of both individuals (e.g. consumers and employees), and collectives (e.g. communities and social networks) (Anderson et al., 2013). Well-being outcomes can include improved physical health, financial wellbeing, or decreased disparity, and therefore differ from traditional service measures focusing on customer satisfaction and loyalty (Rosenbaum, 2015). Examining value creation in TSR, Blocker and Barrios (2015) suggest that transformation occurs when actors break free from their everyday life and critically reflect on present situations and worldviews. This 'breaking free' then brings awareness of new possibilities and ideas that hold the potential for advancing well-being through service innovation. Thereby, innovation concerns changes in the users' role, which subsequently lead to changes in the organization's value creation (Michel et al., 2008). This means that value is not defined by the organization and delivered to consumers in a unidirectional way, but - as conceptualized in recent developments of service-dominant logic - is co-created between multiple actors in many different ways (Vargo and Lusch, 2016). This systemic value creation perspective is fundamental to TSR (Kuppelwieser and Finsterwalder, 2016, Skålén et al., 2015).

TSR has been applied to multiple service settings including health care, finance, education and tourism (Rosenbaum, 2015). Particularly, education and healthcare inherently aim to improve well-being (e.g. Anderson et al., 2018, Mulcahy et al., 2017). Similarly, alcohol education became a key topic in TSR as it offers the potential to enhance the well-being of not only 
individuals (e.g., parents, adolescents) but the collectives (e.g., families, schools, communities) (Dietrich et al., 2017, Durl et al., 2017, Mulcahy et al., 2015). Alcohol-specific programs targeting parents are argued as an important component in minimising alcohol-related risks in adolescents (Newton et al., 2017, Rossow et al., 2016). Key themes that underpin these parentbased programs include knowledge and information awareness on alcohol related topics, parental modelling, enhancing parent-child communication and parental monitoring including family rule setting (Kuntsche and Kuntsche, 2016).

Many education programs have focussed their attention on increasing knowledge, specifically in terms of parental awareness and knowledge of risks and consequences related to underage alcohol consumption (Brown et al., 2014, Perry et al., 2002). While these programs have shown some improvements in parenting practices, particularly an increase in knowledge and awareness of topics concerning adolescent alcohol consumption, their effectiveness remains limited. Specifically, the programs do not effectively facilitate change in parental behaviours (e.g. drinking, monitoring or communication behaviour) towards adolescent alcohol consumption, partly because they are not engaging and do not consider the parents' unique needs (e.g., hectic lifestyles, demanding schedules, short timeframes for tasks) (Toumbourou et al., 2013, Perry et al., 2002). These limitations point to the requirement to explore an approach that starts with a clear understanding of the circumstances surrounding the parents' value creation process. To achieve this, the active involvement of parents during the program design process might be a suitable approach.

Yet, the representation or involvement of end users in the design of existing alcohol education programs is hardly practiced (Kubacki and Rundle-Thiele, 2016). Likewise, studies conducted in TSR point out that design is often pursued by experts with very limited user involvement (Engström and Elg, 2015). Organizations operating in this field often have limited resources available and lack the knowledge required to successfully incentivize and involve users. In 
addition, the time and costs can increase considerably in TSR contexts, because targeted users might not perceive themselves as suitable participants, or might not be willing to participate owing to lacking identification with the underlying organization or the topic in question (Hoyer et al. 2010).

These challenges point to the need for a framework that articulates how user involvement through co-design can be achieved in a TSR context. This is where the present research contributes. By applying co-design to the development of an alcohol education program for parents, this research provides a better understanding of the requirements, challenges, and benefits of its application to transformative service contexts.

\section{Active user involvement through co-design}

Co-design refers to the collective creativity of participants with different background during the design process (Sanders and Stappers, 2008, Steen et al., 2011). It means that experts (i.e., researchers or designers) do not take centre stage in design, but rather play a facilitating role focusing on empowering those who are typically not part of the design process (e.g., consumers, users, or other stakeholders) to share their insights and collectively ideate new services (Dietrich et al., 2017). Thereby, design tools and games can assist experts in facilitating collaboration on a given design content (Mattelmäki and Visser, 2011), managing cross-functional teams (Clatworthy, 2011), and enabling participants to reflect on and communicate their experiences (Blomkvist and Segelström, 2014).

Studies suggest that active user involvement through co-design can have important benefits for the innovating organization, the service design project, and the service users (Steen et al., 2011, Trischler et al., 2018b, Dietrich et al., 2016). For example, Trischler et al. (2018b) find that codesign can lead to key innovation outcomes for the underlying service organization. Other studies show that user-generated ideas are more creative and useful than those developed in- 
house (Kristensson et al., 2004, Magnusson et al., 2003, Poetz and Schreier, 2012). Witell et al. (2011) additionally find that active forms of user involvement, such as co-design practices, are more effective than traditional market research techniques (e.g. focus groups and interviews) because it provides novel insights into latent user needs. It should be noted, however, that these studies involved users with a high level of motivation and ability to contribute to innovation (e.g., leading-edge users); aspects that might not be provided in a TSR context.

Considering these potential benefits of co-design, alongside with the limitations of current expert-driven alcohol education programs, an interesting setup would be to involve users representing the actual target audience (i.e., parents) in the idea generation process of such programs. However, conducting co-design requires careful planning and facilitation. For example, Sanders and Westerlund (2011) provide a general overview of key aspects that need to be considered in co-design practices, which include the recruitment of participants, sensitizing participants to encourage creative thinking, the preparation of material to evoke idea generation, and reflection post event. Ind and Coates (2013) focus on the facilitation process and propose that co-design practitioners should specifically focus on creating an atmosphere that evokes a sense of trust within participants to increase productivity. This argument finds support in a more recent study by Dietrich et al. (2017) finding that the sensitization phase of co-design empowered participants and was important in building a trusting environment.

The examination of the co-design literature suggests that co-design can be approached in a variety of ways (Mattelmäki and Visser, 2011, Trischler et al., 2018a). While there are no frameworks for involving users in a TSR context, the present research adopts the framework by Dietrich et al. (2017), which provides a comprehensive guide for conducting co-design sessions. The framework comprises six steps, including 1) Resourcing, 2) Planning, 3) 
Recruiting, 4) Sensitizing, 5) Facilitation, and 6) Evaluation. Further, while insights across studies suggest that co-design can be an effective approach, it has also been noted that the value of co-design depends on the specific task addressed, users involved, and form of facilitation used (Trischler et al., 2018b). It is therefore important to investigate the application of codesign to the specific instance of TSR, which is a key aim of this study.

\section{Method}

The study utilizes a qualitative approach to understand; 1) how ordinary users can be actively involved in the co-design of transformative services addressing sensitive topics, and 2) how user-driven design ideas differ from expert-driven designs. The use of a qualitative approach enables the exploration of emerging themes and insights that are not restricted to preconceptions (Guba and Lincoln, 1994), which is important for the conceptual development of co-design (Mattelmäki and Visser, 2011).

\section{Participants and study setting}

A purposive sampling method was used to recruit participants for this study. Thereby, the research team initially planned to recruit parents through selected high schools. Further attempts involved intercept recruitment outside a midsize urban supermarket, a university email newsletter, as well as a call for participants via a local politician's newsletter. Yet, all these approaches were not successful. Instead, through a network contact, a call for participants was placed on a restaurant's Facebook page which led to the recruitment of all participants. As incentives, each participant was given a \$AUD 50 voucher and provided with food and drinks during the co-design session. Two co-design sessions were conducted within the respective restaurant involving a total of 24 participants (i.e., 12 participants in Session 1 and 2 respectively). 
Table 1 provides an overview of the participants that were involved in this research. The sample size $(n=24)$ is similar to other exploratory studies conducted within TSR (e.g. Engström and Elg, 2015; Durl et al., 2017). Here it needs to be noted that the focus was on recruiting ordinary users who are typically time-poor. Further, different to studies that involve users who are intrinsically motivated through specific needs (e.g., Poetz and Schreier, 2012; Trischler et al. 2018), the current study targeted users who did not necessarily see themselves as suitable codesign participants owing to their lack of interest and knowledge in the underlying topic.

\section{PLEASE INSERT TABLE 1 ABOUT HERE}

\section{Approach - Application of the six-step co-design framework}

The study adopted the six-step co-design model proposed by Dietrich et al. (2017), which has been suggested as a possible framework for successfully facilitating co-design sessions with vulnerable user groups. Table 2 briefly describes the application of each step.

\section{PLEASE INSERT TABLE 2 ABOUT HERE}

\section{PLEASE INSERT FIGURE 1 ABOUT HERE}

At the beginning of the co-design session, the participants were randomly assigned to groups consisting of four to five members. In each group a facilitator was present for the duration of the activity. In addition, each participant received eight activity cards (see Figure 1). Each card contained a brief summary of an existing alcohol education program component specifically targeted at parents ${ }^{1}$. The facilitator first asked participants to review the cards and then started an open discussion on opinions of the existing alcohol education programs. This introductory activity has been suggested as useful to allow participants to reflect on the status-quo and initiate an idea generation process (Ind and Coates, 2013, Dietrich et al., 2016). 
Following from the in-group discussions, participants were asked to develop ideas that built on the activity cards discussed in the preceding stage and/or generate completely new ideas. In addition, parents were instructed to think about key features of the new ideas with regards to the program platform (e.g. online, face to face, individual, group), its content (e.g. whether the program should involve the adolescent in any components), and the duration of the program. Thereby, participants were once more randomly allocated into groups of three to four. This reassembling of groups enables a 'breaking free' from the initial group discussions with the facilitator. Specifically, doing so is important to reduce the influence of the facilitator during the idea generation process (Trischler et al., 2017).

To support participants in the generation of new ideas, 'make tools' were allocated to each group and included butcher paper, pens, coloured markers, stickers and pencils. These tools encourage creative collaborations among participants from different backgrounds, as well as assist in the uncovering and communication of latent needs because they are primarily visual and offer a language which is understood by designers and non-designers alike (Brandt, 2006, Sanders et al., 2010). The co-design sessions concluded with each group presenting their generated ideas to the entire audience.

\section{Data collection}

Data was collected in three ways. Firstly, the in-group discussions were audio-taped with voice recording devices used within each group. Secondly, the idea presentations at the end of the sessions were filmed and photographs were taken of each design idea. Across both sessions this resulted in a total of five audio recordings of the in-group discussions and two video recordings of the final idea presentations. The recordings were transcribed using a professional transcription service. Finally, field notes were taken independently by each of the three facilitators during and immediately after the co-design sessions. The focus was on documenting 
any peculiarities within the groups, including group dynamics, forms of participation by individuals, difficulties or challenges faced by the groups, and the process followed during the idea generation.

\section{Data analysis}

The data was analysed by following the five-phase cycle recommended by Yin (2015). Specifically, the transcribed data was first compiled into a database using Microsoft Word. The database consisted of two separate reports (one for each co-design session) which were organised using topic headings in order to make the raw data more manageable. This involved placing the data derived from the in-group discussions under headings related to each activity card (e.g. social trivia night, teen party simulation, prevention postcards, etc.). Next, the compiled data was disassembled using an open coding process of assigning codes to the transcribed sessions (Hahn, 2008). During the open coding process, the focus was on identifying aspects that participants perceived as important for an effective alcohol education program including its content and features. The data was then reassembled using Microsoft Excel Spreadsheets, by re-examining the open codes and creating category codes that further focused the data (see Table 3 for examples of the coding process). As part of an iterative process, the data procedure was repeated multiple times as the codes and themes were reviewed and further refined.

The program ideas that were generated by parents as a result of the two co-design sessions (a total of seven) were analysed by assessing the key components and features of each idea (see Table 4). Specifically, each idea was assessed in terms of platforms utilized, the content delivered (e.g. parental monitoring, parental modellings), the level of adolescent involvement and the duration of the program. These components were chosen for the analysis as participants were requested to consider each of these factors when designing their programs during the co- 
design sessions. The analysis of the parent-designed ideas, alongside with the insights from the in-group discussions, led to the identification of three overarching themes that underlined key aspects parents placed value on in an alcohol education program.

\section{PLEASE INSERT TABLE 3 ABOUT HERE}

\section{Findings}

The analysis procedure as discussed above led to the development of specific themes that indicated differences to existing expert-designed programs. Each theme is described in further detail below and demonstrates how users-driven design ideas differ from those designed by experts (as asked in RQ2).

\section{PLEASE INSERT TABLE 4 ABOUT HERE}

\section{User driven design ideas versus expert design ideas}

Usability means flexibility. The utilisation of multiple platforms (i.e., face to face, online, postal materials) to deliver the materials was identified by parents as an important feature as it adds versatility to programs. It was stated that programs should include "changing platforms and delivery of information through that time, so it wasn't just about one form of delivery." (Female

participant, Session 1). However, online or postal delivery platforms were not seen as being suitable in any of the co-designed programs as a sole component. Instead these were integrated as possible 'support platforms' to provide a more holistic form of program delivery. Parents felt that while postal materials would be a good prompt to start communications, these materials would require prior advice and knowledge in order to ensure effective implementation. As one participant described: "So, it would have to be done with something else so you can explain the strategies. I don't think it could just be done like that, just get a postcard and say, here's here's what we have to talk about and why. Yeah, you'd have to understand why you're talking about that" (Female participant, Session 2). 
The use of more than one platform to deliver the materials was implemented in $86 \%$ of the codesigned programs. As a comparison, 55\% of expert-designed programs utilize just a single platform. In addition, one third of the expert programs utilized online and/or postal materials as the sole component of the program. In terms of platforms design, this finding shows that parents place value on programs which integrate a variety of delivery modes. Nonetheless, a face to face component is still regarded as an essential feature becausee it allows the parents to engage with the program in an environment that permits questions and feedback. This then provides them with sufficient knowledge and confidence on how to use supporting components more independently.

We are in this together so let's tackle it this way. The participants highlighted the importance of involving adolescents in some components of the parent program. As one parent stated, "I actually really like the idea of anything that you're doing with the kids so that you're both hearing the same thing and you can have those discussions later on" (Female participant, Session 1). However, it was also noted that adolescent involvement should depend on the specific content and purpose of the respective program. For example, material on how to monitor adolescents was deemed relevant for parents only, as these included practical tips specifically for parents to learn and later implement in their household: "I wouldn't be telling my son how I was going to monitor him. But if I'd known some few other ways of monitoring him, that might have been helpful" (Male participant, Session 2).

While $71 \%$ of the co-designed programs included activities involving both parents and adolescents, only $44 \%$ of the expert-designed programs featured adolescent involvement. Following these insights, it is recommended that while adolescents should be involved in alcohol education programs, designers need to carefully consider which activities are appropriate for both, parents and adolescents. For example, while parental monitoring and modelling content is relevant for parents only, both the parent and adolescent may be involved 
when content focuses on improving parent-child communication and increasing knowledge and awareness surrounding alcohol related topics.

Time is money. A deterrent for parents were programs that went for more than one hour and included multiple face-to-face sessions (e.g. a session a week for eight weeks). Parents stated that if the duration of an activity was perceived as too long they were less likely to attend even when they perceive its content as relevant: “Knowing about it is really important, but I can't see myself going to somewhere for two hours" (Female participant, Session 1).

In addition, the participants clearly preferred programs that involved supporting components that did not require an extensive time commitment and/or could be completed in their own time (e.g., online and postal materials). This finding is in contrast to existing programs, with $44 \%$ of the expert-designed program activities requiring parents to commit to weekly sessions from 1 to 2.5 hours for a duration of six to eight weeks. It is therefore suggested that programs should involve parents committing to a single face-to-face activity and followed by activities using different platforms (e.g., online, postal materials) in order to provide them with relevant information.

Linking the design with the user's value creation process. Overall, the insights generated from the co-design sessions contributed to a program design that has the potential to more effectively support parents in creating value based on the specificity of their context. The participants described specific benefits that these education programs can have in their lives. As one participant described: “It's going to present, the issues that are relevant today, as opposed to issues that were relevant back when we were teenagers" (Female participant, session 2). Yet parents, who represent the actual target group of the underlying program, are time-poor and therefore not able to commit substantive time to completing these programs. Their daily life 
also does not allow for a systematic schedule, which means that flexibility is key in the design of the program activities.

Finally, parents shared difficulties they had in making their points, and communicating effectively, to adolescents:

"It sounds kind of like Big Brother, but with devices now, it's really difficult for families to monitor everything that their kids are doing” (Female participant, session 2).

"Yeah, and they always go '... what do you know mum', whereas if you're hearing the same thing" (Female participant, session 1).

Program activities that involve adolescents into the learning process appear to be an effective way to overcome these challenges because in this way activities are not perceived as something originating from parents trying to lecture their children, but as an initiative from an external party. It points towards the importance of understanding the specific circumstances, including the social context, in which value is created (Edvardsson et al., 2011, Trischler et al., 2018b).

The next section builds on these findings by discussing its implications for service research and practice. This is done as part of a critical reflection on the six-step co-design model in its application to a TSR context.

\section{Implications for applying co-design to TSR}

\section{Reflections and theoretical contributions}

This study contributes to the important questions of how users can be involved through codesign (RQ1) and what contribution they can make to service innovation (RQ2). Studies that investigate the effect of user involvement in innovation processes have mostly focused on selected users, such as lead users, market mavens, and brand loyal consumers, or business-tobusiness contexts where the distance between the organization and client is typically smaller 
(e.g., Hoyer et al., 2010, Trischler et al., 2017). In contrast, relatively little insights are available on the involvement of ordinary users (i.e. users who are not typically equipped with the technical skills or a detailed knowledge of the service) and their contribution to the service innovation process (Ostrom et al., 2015).

In this section, the six-step co-design model proposed by Dietrich et al. (2017) is critically examined in terms of its applicability to the current context; that is, a TSR context addressing a sensitive topic and involving ordinary users who might not perceive themselves as suitable participants. The data that informed this examination included the researchers' experiences and reflections throughout the early stages of the co-design process (i.e. resourcing, planning, and recruitment), as well as data derived from the field notes that were taken by the research team members (i.e. sensitizing and facilitation). The evaluation stage was informed by the

photographs and presentations of the design ideas. Doing so enabled the identification of requirements, challenges, and benefits for applying co-design to transformative services along each of the six co-design stages. Table 5 provides an overview of the key aspects that need to be considered in the application of co-design to TSR.

\section{PLEASE INSERT TABLE 5 ABOUT HERE}

Step 1 Resourcing: The identification of previous programs during the resourcing stage provided the research team with a better understanding of the current practices surrounding alcohol education resources for parents. In addition, a critical examination of current parent programs was required to allow for the identification of relevant themes and activities which assisted in the development of the co-design tools (e.g. activity cards).

Step 2 Planning: Regular meetings with the research team were necessary to facilitate the planning of each of the following stages (i.e. recruitment, sensitizing, facilitation and 
evaluation). The planning stage was also important to network the co-design session and underlying topic to create awareness among stakeholders and the targeted user groups.

Step 3 Recruiting: The recruitment stage was found to be the key determinant of the co-design project moving forward or not. Hereby, strong network links were needed to communicate the co-design project, including the contributions parents could make through their participation. Different access points were used to do this. For example, a member of a local parliament, as well as various high schools within the respective area, were approached to gain access to parents. Although these parties supported the initiatives, the parents when invited via newsletters and parent evenings organised by the schools, were not interested in participating. This lack of interest might have been a result of the underlying topic being an 'avoidance topic'; that is, sensitive and non-engaging in nature which is common in TSR contexts. This includes topics that individuals may refrain from communicating (e.g. drug abuse, violence, inequality, poverty and racism) (Engström and Elg, 2015).

A network link with the owner of a local restaurant ultimately led to the successful recruitment of participants. The owner of the restaurant placed a post on the business's Facebook page, advertising the co-design sessions. The social media channel has over 6,000 followers and a strong community connection. The owner's commitment in driving the initiative, as well as the close relationship between the business with customers representing the targeted user group, attracted a sufficient number of participants. It is important to consider these challenges in TSR, and identify an effective recruitment strategy in order to avoid an inflation of costs and time commitment to the project.

The above challenges related to recruitment explain why active user involvement is hardly practiced in the public service sector (Engström et al., 2015). This study shows that tapping strong social networks can lead to higher commitment from key stakeholders, such as 
proactively marketing the projects, which makes the recruitment process less time- and resource-intensive. Importantly, once recruited and sensitized, the involved users were eager to contribute their unique knowledge and skills to the design of new service ideas. This change in willingness can be leveraged during the co-design process by setting an environment of playfulness and trust (e.g., Ind and Coates, 2013, Dietrich et al., 2017, Mattelmäki and Visser, 2011). As is described further below, facilitating such an environment is particularly relevant for addressing TSR topics.

Step 4 Sensitizing: Owing to the difficulties in recruiting the participants, several of the strategies defined during the planning stage could not be implemented. For example, as the research team had difficulties in obtaining direct contact to parents, the planned sensitizing process prior to the co-design sessions was deemed infeasible, and instead was restructured to be included during the facilitation stage. Instead, sensitizing was restructured to be included directly into the facilitation stage. This involved the introduction of the underlying topic and design tasks followed by an in-group discussion of existing alcohol education programs by using activity cards.

Step 5 Facilitation: Three requirements were identified for facilitating co-design successfully. Firstly, the application of suitable design tools was necessary to sensitize participants with the underlying topic and empower them to contribute actively to the generation of new ideas. Thereby, the use of activity cards enabled participants to sensitize with the topic at hand through exposure to existing parent alcohol education program activities, while also promoting idea generation. For example, the cards enabled participants to develop an initial understanding of components and factors that they did or did not like in existing activities and discussing initial ideas for improvement or alternative activities. In addition, the use of these cards reduced the dominance of the facilitator (e.g. there was no need to describe each activity), which led to a more open-discussion and a trusting environment between the participants. 
Secondly, during the idea generation process a key requirement was close guidance of the groups to ensure progress and outcomes that align with the set targets. During the ideation phase the research team observed the groups, and offered support when it appeared that a group was having difficulties. The groups repeatedly swayed from the task at hand and engaged in off-topic discussions. In fact, an important condition for the idea development phase was finding a common ground within the individual groups on what ideas should be developed. It was during this phase, where the participating researchers took a key role in ensuring progress towards an agreed outcome (i.e. to develop a program that parents would find relevant, engaging and would be willing to attend). Yet, as also highlighted by Kimbell (2012), researchers or experts should take the role less as designers but as facilitators, tasked with empowering the participants to contribute equally as 'experts of their experience'.

Thirdly, the co-design sessions concluded with a short presentation of the developed ideas from each group. This allowed participants to share their insights and describe the developed ideas in their own words. Doing so ensured that the research team fully understood the content and purpose of the generated ideas. In addition, this concluding phase served a celebrative purpose to recognize everyone's contribution, which can lead to a shared sense of accomplishment (Donetto et al., 2015).

Step 6 Evaluation: The evaluation process was important to systematically incorporate key findings from the co-design sessions into the subsequent program design stages. This included the analysis of the transcripts of the in-group discussions as well as final idea presentations alongside with the photographs of the produced design ideas.

The evaluation of ideas supports the importance of actively involving users for leveraging service success (Trischler et al., 2017, Melton and Hartline, 2015). It is the user who creates value in their specific context (Vargo and Lusch, 2008), implying that the design and provision 
of a value proposition needs to essentially start with clearly understanding the specific circumstances surrounding their value creational processes (Gustafsson et al., 2012). Specifically, the present study shows from a TSR perspective that ordinary users (i.e., parents) can contribute to ideas that have the potential to improve well-being, not only on the individual (e.g., better access to alcohol education) but also on the collective level (e.g., addressing alcohol-related problems within society). Even the relatively short involvement in the design process triggered awareness among the participants about their roles within the current social structures and the active contributions they can make to improving their own and others wellbeing.

\section{PLEASE INSERT TABLE 6 ABOUT HERE}

Based on the conceptualisation by Michel et al. (2008), Table 6 provides an overview of the users' contribution to service innovation. Parents contributed ideas that change existing education programs towards new ways of defining the users' role (e.g. integrating flexibility during the learning process; redefining the role of adolescents), and how the service provider creates value with users (e.g., modifying existing programs by allowing different ways of resource integration). These changes enabled the project team to make the programs more engaging and to align its content with the context-specific requirements of the respective user group (e.g. suitable for the target group's hectic lifestyle). As a result, the access to and impact of alcohol education will be improved, which leads to more informed decisions and practices surrounding alcohol.

\section{Practical implications}

This study provides several important insights for organizations seeking to apply co-design to TSR projects. Firstly, careful planning of the co-design activity is required, specifically in terms of recruiting and sensitizing suitable participants. To gain access to a sufficient pool of 
participants, organizations should utilize their networks and relationships with local community centres, sports clubs, restaurants, and schools. Within these networks, the first step should focus on sensitizing the community about the importance of addressing the underlying topic and making people aware of the contribution they can make to service innovation.

During the facilitation stage, the application of design tools should be used to enable participants to utilize their specific skills and knowledge for ideating new service solutions. The insights generated from this study suggest, that facilitators should directly guide and support the teams in order to ensure that the generated outcomes align with the project aims. Nonetheless, the facilitator needs be careful to not constrict participants in their creativity and contributions. Finally, concluding presentations of the developed ideas from each team can bring a sense of accomplishment into the team, while also ensuring that each design idea is interpreted correctly by those responsible of developing the idea further.

Organizations might ask as to whether the time and costs of involving users through co-design does actually lead to improved outcomes. As this study shows, ordinary users can within a relatively short timeframe provide important insights into their specific circumstances surrounding their value creation process. In the current context, expert-driven programs have indicated difficulties with engaging the target audience (i.e., parents) and have shown limited success in changing well-being outcomes (Perry et al., 2002, Toumbourou et al., 2013). In fact, the user-designed ideas differed substantially from the expert-designed programs, particularly in terms of changes that enable parents to more effectively integrate alcohol education into their everyday life. As a result, a new program design could be developed that provides a more suitable configuration of resources for the respective target audience to integrate and operate on.

\section{Limitations and future research}


This research is not without limitations. Firstly, the generalizability of the research findings is limited to one study setting and a narrow defined sample. The specific setup means that the requirements for, and consequences of, co-design might vary in accordance to the design task addressed and the specific participants involved. For example, it might be easier to recruit user groups that are less time poor or easier accessible. In turn, the involvement of vulnerable consumers (e.g., children or adolescents), might require a different facilitation approach. Organizations should account for these possible unique requirements during the planning stage of the co-design sessions. For future research, it is important to apply co-design to other TSR contexts in order to explore possible additional or alternative challenges and requirements.

Secondly, this study only focused on the ideation stage and a very specific form of user involvement, that is, a team approach. Co-design can be approached in a variety of ways (Mattelmäki and Visser, 2011), and a team approach can lead to the occurrence of various intrateam factors that might affect the collaborative design process and outcomes (Trischler et al., 2017). Here a possible avenue for future research could be studies that systematically compare the process and outcomes of different co-design approaches. Apart from comparing user involvement on a team basis $v s$. an individual basis, also the roles and impact of the facilitators should be considered.

Finally, the study used one specific way of evaluating the generated ideas, namely the framework by Michel et al. (2008). This framework builds on service-dominant logic asserting that service innovations are not defined in terms of new features, but value propositions that either integrate newly invented resources, or existing resources in a different way (Lusch and Nambisan, 2015). While this perspective aligns well with the current approach to service design, other outcome evaluation frameworks might allow a more systematic evaluation (e.g., Magnusson et al., 2016) or align more closely to the context of TSR (e.g., Anderson et al., 2013). Particularly the development of an instrument that considers well-being outcomes for 
both individuals and the collective will be important for allowing a more systematic evaluation of TSR-related innovation efforts.

\section{Conclusion}

Co-design is a suitable method that enables users to contribute their unique knowledge and skills to the design of new service ideas. When applied to TSR contexts, organizations will face a number of challenges, particularly during the recruitment and facilitation stages. Yet, organizations should not get discouraged from these challenges because users can contribute important insights that might be overlooked by conventional market research techniques. In fact, as this study shows the user-generated outcomes differed substantially from the expertdesigned programs, particularly in terms of changes that enable parents to more effectively integrate alcohol education into their everyday life. This research contributes to a better understanding of the specific requirements, challenges, and benefits that follow from the application co-design to service innovation activities that concern transformative aims.

\section{Notes:}

${ }^{1}$ The components were sourced from a comprehensive desk research on existing parent-based alcohol education programs. 


\section{References}

Anderson, L. \& Ostrom, A. L. (2015), Transformative service research: advancing our knowledge about service and well-being. Journal of Service Research, Vol. 18 No. 3, pp. 243-249.

Anderson, L., Ostrom, A. L., Corus, C., Fisk, R. P., Gallan, A. S., Giraldo, M., Mende, M., Mulder, M., Rayburn, S. W. \& Rosenbaum, M. S. (2013), "Transformative service research: an agenda for the future". Journal of Business Research, Vol. 66 No. 8, pp. 1203-1210.

Anderson, S., Nasr, L. \& Rayburn, S. W. (2018), "Transformative service research and service design: synergistic effects in healthcare". The Service Industries Journal, Vol. 38 No. 1-2, pp. 99-113.

Australian National Prevention Health Agency (2014), Alcohol in Australia. Retrieved from http://health.gov.au/internet/anpha/publishing.nsf/Content/draft-report-alcoholadvertising+ chapter +-1 (accessed 12 June 2017).

Blocker, C. P. \& Barrios, A. (2015), "The Transformative Value of a Service Experience". Journal of Service Research, Vol. 18 No. 3, pp. 265-283.

Blomkvist, J. \& Segelström, F. (2014), "Benefits of external representations in service design: A distributed cognition perspective". The Design Journal, Vol. 17 No. 3, pp. 331-346.

Brandt, E. (2006), Designing exploratory design games: a framework for participation in Participatory Design? Proceedings of the ninth conference on Participatory design: Expanding boundaries in design, Vol 1, pp. 57-66.

Brown, P. C., Dunn, M. E. \& Budney, A. J. (2014), "Development and Initial Evaluation of a Web-Based Program to Increase Parental Awareness and Monitoring of Underage Alcohol Use: A Brief Report". Journal of Child \& Adolescent Substance Abuse, Vol. 23 No. 2, pp. 109-115.

Clatworthy, S. (2011), "Service innovation through touch-points: Development of an innovation toolkit for the first stages of new service development". International Journal of Design, Vol. 5 No. 2, pp. 15-28.

Dietrich, T., Rundle-Thiele, S., Schuster, L. \& Connor, J. (2016), "Co-designing social marketing programs". Journal of Social Marketing, Vol. 6 No. 1, pp. 41-61.

Dietrich, T., Trischler, J., Schuster, L. \& Rundle-Thiele, S. (2017), "Co-designing services with vulnerable consumers". Journal of Service Theory and Practice, Vol. 27 No. 3, pp. 663-688.

Donetto, S., Pierri, P., Tsianakas, V. \& Robert, G. (2015), "Experience-based co-design and healthcare improvement: Realizing participatory design in the public sector". The Design Journal, Vol. 18 No. 2, pp. 227-248. 
Durl, J., Trischler, J. \& Dietrich, T. (2017), "Co-designing with young consumersreflections, challenges and benefits". Young Consumers, Vol. 18 No. 4, pp. 439-455.

Edvardsson, B., Tronvoll, B. \& Gruber, T. (2011), "Expanding understanding of service exchange and value co-creation: a social construction approach". Journal of the Academy of Marketing Science, Vol. 39 No. 2, pp. 327-339.

Engström, J. \& Elg, M. (2015), "A self-determination theory perspective on customer participation in service development". Journal of Services Marketing, Vol. 29 No. 6/7, pp. 511-521.

Engström, J., Elg, M., Poksinska, B., Witell, L. \& Snyder, H. (2015), "The role of customers in the development of public organizations". Sustainable Development in Organizations: Studies on Innovative Practices, Vol. No., pp. 93-108.

Guba, E. G. \& Lincoln, Y. S. (1994), "Competing paradigms in qualitative research". Handbook of qualitative research, Vol. 2 No. 163-194, pp. 105-117.

Gustafsson, A., Kristensson, P. \& Witell, L. (2012), "Customer co-creation in service innovation: a matter of communication?". Journal of Service Management, Vol. 23 No. 3, pp. 311-327.

Hogan, S. P., Perks, K. J. \& Russell-Bennett, R. (2014), "Identifying the key sociocultural influences on drinking behavior in high and moderate binge-drinking countries and the public policy implications". Journal of Public Policy \& Marketing, Vol. 33 No. 1, pp. 93-107.

Hoyer, W. D., Chandy, R., Dorotic, M., Krafft, M. \& Singh, S. S. (2010), "Consumer cocreation in new product development". Journal of service research, Vol. 13 No. 3, pp. 283-296.

Ind, N. \& Coates, N. (2013), "The meanings of co-creation". European Business Review, Vol. 25 No. 1, pp. 86-95.

Jaakkola, E., Meiren, T., Witell, L., Edvardsson, B., Schäfer, A. (2017), "Does one size fit all? New service development across different types of services". Journal of Service Management, Vol. 28 No. 2, pp. 329-347.

Kimbell, L. (2012), "Rethinking design thinking: Part II". Design and Culture, Vol. 4 No. 2, pp. 129-148.

Kristensson, P., Gustafsson, A. \& Archer, T. (2004), "Harnessing the creative potential among users". Journal of product innovation management, Vol. 21 No. 1, pp. 4-14.

Kubacki, K. \& Rundle-Thiele, S. (2016), Formative Research in Social Marketing: Innovative Methods to Gain Consumer Insights, Springer.

Kuntsche, S. \& Kuntsche, E. (2016), "Parent-based interventions for preventing or reducing adolescent substance use-A systematic literature review". Clinical psychology review, Vol. 45 No., pp. 89-101. 
Kuppelwieser, V. G. \& Finsterwalder, J. (2016), "Transformative service research and service dominant logic: Quo Vaditis?". Journal of Retailing and Consumer Services, Vol. 28 No., pp. 91-98.

Lusch, R. F. \& Nambisan, S. (2015), "Service innovation: A service-dominant logic perspective". Mis Quarterly, Vol. 39 No. 1, pp. 155-175.

Magnusson, P. R., Matthing, J. \& Kristensson, P. (2003), "Managing user involvement in service innovation: Experiments with innovating end users". Journal of Service Research, Vol. 6 No. 2, pp. 111-124.

Magnusson, P. R., Wästlund, E. \& Netz, J. (2016), "Exploring users' appropriateness as a proxy for experts when screening new product/service ideas". Journal of Product Innovation Management, Vol. 33 No. 1, pp. 4-18.

Mattelmäki, T. \& Visser, F. (2011) Published. Lost in Co-X: Interpretations of Co-design and Co-creation. 4th World Conference on Design Research (IASDR 2011). Delft, Netherlands.

Melton, H. \& Hartline, M. D. (2015), "Customer and employee co-creation of radical service innovations". Journal of Services Marketing, Vol. 29 No. 2, pp. 112-123.

Michel, S., Brown, S. W. \& Gallan, A. S. (2008), "An expanded and strategic view of discontinuous innovations: deploying a service-dominant logic". Journal of the Academy of Marketing Science, Vol. 36 No. 1, pp. 54-66.

Mulcahy, R., Russell-Bennett, R. \& Rundle-Thiele, S. (2015), "Electronic games: can they create value for the moderate drinking brand?". Journal of Social Marketing, Vol. 5 No. 3, pp. 258-278.

Mulcahy, R., Russell-Bennett, R., Zainuddin, N. \& Kuhn, K.-A. (2017), "Designing gamified transformative and social marketing services: An investigation of serious m-games". Journal of Service Theory and Practice, Vol. 28 No. 1, pp. 26-51.

Newton, N. C., Champion, K. E., Slade, T., Chapman, C., Stapinski, L., Koning, I., Tonks, Z. \& Teesson, M. (2017), "A systematic review of combined student-and parent-based programs to prevent alcohol and other drug use among adolescents". Drug and Alcohol Review, Vol. 36 No. 3, pp. 337-351.

Ostrom, A. L., Parasuraman, A., Bowen, D. E., Patricio, L. \& Voss, C. A. (2015), "Service research priorities in a rapidly changing context". Journal of Service Research, Vol. 18 No. 2, pp. 127-159.

Patrício, L. \& Fisk, R. P. (2013), "Creating new services". In R. P. Fisk, R. Russell-Bennett \& L. C. Harris (Eds.), Serving Customers: Global Services Marketing Perspectives, Brisbane: Tilde University Press, pp. 185-207.

Perry, C. L., Williams, C. L., Komro, K. A., Veblen-Mortenson, S., Stigler, M. H., Munson, K. A., Farbakhsh, K., Jones, R. M. \& Forster, J. L. (2002), "Project Northland: Long- 
term outcomes of community action to reduce adolescent alcohol use". Health education research, Vol. 17 No. 1, pp. 117-132.

Poetz, M. K. \& Schreier, M. (2012), "The value of crowdsourcing: can users really compete with professionals in generating new product ideas?". Journal of Product Innovation Management, Vol. 29 No. 2, pp. 245-256.

Rosenbaum, M. S. (2015), Transformative service research: research that matters, The Service Industries Journal, Vol. 35 No. 15-16, pp. 801-805.

Rossow, I., Keating, P., Felix, L. \& Mccambridge, J. (2016), "Does parental drinking influence children's drinking? A systematic review of prospective cohort studies". Addiction, Vol. 111 No. 2, pp. 204-217.

Russell-Bennett, R., Drennan, J., Raciti, M., Bowring, N. \& Burns, K. (2017), "Using service design to understand digital preferences for improving applications for tertiary education in under-represented markets".

Russell-Bennett, R., Leo, C., Rundle-Thiele, S. \& Drennan, J. (2016), "A hierarchy-of-effects approach to designing a social marketing game". Journal of Nonprofit \& Public Sector Marketing, Vol. 28 No. 2, pp. 105-128.

Sanders, Brandt, E. \& Binder, T. (2010), "A framework for organizing the tools and techniques of participatory design". In Proceedings of the 11th biennial participatory design conference, Sydney: Australia.

Sanders \& Stappers, P. J. (2008), "Co-creation and the new landscapes of design". Co-design, Vol. 4 No. 1, pp. 5-18.

Sanders \& Westerlund, B. (2011), "Experiencing, exploring and experimenting in and with co-design spaces". In Proceedings of the Nordic Design Research Conference, Helsinki, Finnland.

Skålén, P., Aal, K. A. \& Edvardsson, B. (2015), "Cocreating the Arab Spring: Understanding transformation of service systems in contention". Journal of Service Research, Vol. 18 No. 3, pp. 250-264.

Steen, M., Manschot, M. \& De Koning, N. (2011), "Benefits of co-design in service design projects". International Journal of Design, Vol. 5 No. 2, pp. 53-60.

Toumbourou, J. W., Gregg, M. E. D., Shortt, A. L., Hutchinson, D. M. \& Slaviero, T. M. (2013), "Reduction of Adolescent Alcohol Use Through Family-School Intervention: A Randomized Trial". Journal of Adolescent Health, Vol. 53 No. 6, pp. 778-784.

Trischler, J., Kristensson, P. \& Scott, D. (2018a), "Team diversity and its management in a co-design team". Journal of Service Management, Vol. 29 No. 1, pp. 120-145.

Trischler, J., Pervan, S. \& Scott, D. R. (2017), "Exploring the 'black box'of customer cocreation processes". Journal of Services Marketing, Vol. 31 No. 3, pp. 265-280. 
Trischler, J., Pervan, S. J., Kelly, S. J. \& Scott, D. R. (2018b), "The Value of Codesign: The Effect of Customer Involvement in Service Design Teams". Journal of Service Research, Vol. 21 No. 1, pp. 75-100.

Vargo, S. L. \& Lusch, R. F. (2008), "Service-dominant logic: continuing the evolution". Journal of the Academy of marketing Science, Vol. 36 No. 1, pp. 1-10.

Vargo, S. L. \& Lusch, R. F. (2016), "Institutions and axioms: an extension and update of service-dominant logic". Journal of the Academy of Marketing Science, Vol. 44 No. 1, pp. 5-23.

Williams, Marsiglia, Baldwin \& Ayers (2015), "Unintended Effects of an Intervention Supporting Mexican-Heritage Youth: Decreased Parent Heavy Drinking". Research on Social Work Practice, Vol. 25 No. 2, pp. 181-189.

Witell, L., Kristensson, P., Gustafsson, A. \& Löfgren, M. (2011), "Idea generation: customer co-creation versus traditional market research techniques". Journal of Service Management, Vol. 22 No. 2, pp. 140-159.

Yam, A., Russell-Bennett, R., Foth, M. \& Mulcahy, R. (2017), "How Does Serious M-Game Technology Encourage Low-Income Households To Perform Socially Responsible Behaviors?". Psychology \& Marketing, Vol. 34 No. 4, pp. 394-409.

Yin, R. K. (2015), Qualitative research from start to finish, New york: NY, The Guilford Press. 
Table 1: Overview of participants

\begin{tabular}{llllllll} 
Session 1 & \multicolumn{7}{c}{ Session 2 } \\
\hline ID & Age & Gender & $\begin{array}{l}\text { Nrof } \\
\text { children }\end{array}$ & ID & Age & Gender & $\begin{array}{l}\text { Nr of } \\
\text { children }\end{array}$ \\
\hline Kathryn & 43 & $\mathrm{~F}$ & 4 & Mark & 45 & $\mathrm{M}$ & 3 \\
Helen & 47 & $\mathrm{~F}$ & 2 & Adam & 52 & $\mathrm{M}$ & 2 \\
Sharyn & 54 & $\mathrm{~F}$ & 3 & Tracey & 38 & $\mathrm{~F}$ & 2 \\
Prue & 40 & $\mathrm{~F}$ & 4 & Adrian & 63 & $\mathrm{M}$ & 2 \\
Akiko & 46 & $\mathrm{~F}$ & 1 & Sam & 42 & $\mathrm{M}$ & 2 \\
Kath & 44 & $\mathrm{~F}$ & 4 & Lisa & 35 & $\mathrm{~F}$ & 3 \\
Kim & 45 & $\mathrm{~F}$ & 3 & Ann & 43 & $\mathrm{~F}$ & 3 \\
Jonathan & 51 & $\mathrm{M}$ & 2 & Belinda & 43 & $\mathrm{~F}$ & 2 \\
Sarah & 40 & $\mathrm{~F}$ & 3 & Glen & 44 & $\mathrm{M}$ & 1 \\
Helen & 45 & $\mathrm{~F}$ & 3 & Hugh & 53 & $\mathrm{M}$ & 2 \\
Lea & 42 & $\mathrm{~F}$ & 3 & Brendan & 68 & $\mathrm{M}$ & 1 \\
Amy & 50 & $\mathrm{~F}$ & 2 & Matt & 50 & $\mathrm{M}$ & 1 \\
\hline
\end{tabular}


Table 2: Application of six-step co-design model

\section{Process stage Application to a TSR Context}

1. Resourcing - Relevant input was sourced from peer-reviewed articles and a secondary literature search across major search engines.

- Previous parent-based alcohol education programs were identified and assessed, and clustered into keys themes which allowed for the creation of the activity cards to be used during the co-design session (examples are depicted in Figure 1).

2. Planning

- Regular meetings were held with the research team to co-ordinate the planning of the co-design sessions.

- Desired goals and outcomes of each stage were articulated and planned for.

3. Recruiting

- Suitable stakeholders who could facilitate access to parents were identified.

- Suitable participants were identified and recruited.

4. Sensitizing

- The planned sensitizing stage was not implemented due to recruitment challenges.

- Instead, participants were sensitized during the facilitation stage with the use of the design tools.

5. Facilitation

The co-design sessions were split into four stages

1. Introduction: Participants were made aware of the purpose and nature of the study and sensitised with the topic.

2. Card Sorting (Part I): Participants were provided with co-design tools (i.e. activity cards) and instructed to individually read through all activities and sort the activities into 'likes' and 'dislikes'.

3. Card Sorting (Part II): Facilitators encouraged an open discussion on each of the eight activities within groups.

4. Ideation: Using 'make tools', participants were asked to generate ideas for a novel or improved parent alcohol program that they felt would be more relevant and engaging.

- A five-phase cycle recommended by Yin (2011) was applied to develop themes out of the qualitative data. 
Figure 1: Activity cards examples

\begin{tabular}{|l|l|}
\hline \multicolumn{1}{|c|}{$\begin{array}{c}\text { Problem posing with discussion } \\
\text { Knowledge/ awareness }\end{array}$} \\
\hline $\begin{array}{l}\text { Format. Workshop } \\
\text { Duration: } 1 \text { hour }\end{array}$ \\
$\begin{array}{l}\text { Content Thought provoking questions are } \\
\text { presented to parents which aim to } \\
\text { encourage discussions about issues } \\
\text { related to alcohol among youths and } \\
\text { parents. The aim is to increase awarenss } \\
\text { about the issue of alcohol among youths } \\
\text { and the role parents play in intervening and } \\
\text { preventing or moderating alcohol use by } \\
\text { their child. }\end{array}$ \\
\hline
\end{tabular}

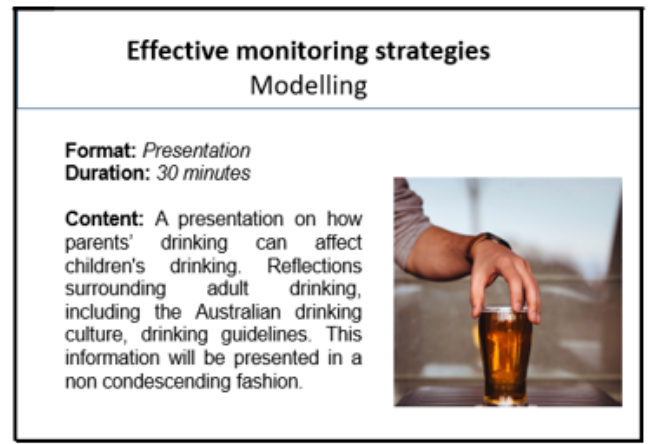


Table 3: Examples of coding process

Raw text that inspired the codes

Open code

Category code

Theme

"Changing platforms and delivery of

Multiple forms of delivery

Incorporate multiple platforms

Usability means flexibility

information through that time, so it wasn't

just about one form of delivery."

"So, it would have to be done with something else so you can explain the strategies. I don't think it could just be

done like that, just get a postcard and say, here's - here's what we have to talk about and why. Yeah, you'd have to understand why you're talking about that."

I wouldn't be telling my son how I was going to monitor him. But if I'd known some few other ways of monitoring him, that might have been helpful."

"I actually really like the idea of anything that you're doing with the kids so that you're both hearing the same thing and you can have those discussions later on."

"I have put it in dislike, because I think if it involves the children, they would just

Postal as supporting component

Incorporate multiple platforms

Usability means flexibility
Adolescent involvement in activities
Monitoring for parents only Level of adolescent involvement

Level of adolescent involvement

Activity for parent only
Level of adolescent involvement
We are in this together so let's tackle it this way

We are in this together so let's tackle it this way straight up think that's ridiculous." 
Table 4: Co-designed parent programs

\begin{tabular}{|c|c|c|c|c|c|c|c|c|c|c|c|}
\hline \multirow[b]{2}{*}{ Program Name } & \multirow[b]{2}{*}{ Platform } & \multirow[b]{2}{*}{ Duration } & \multirow[b]{2}{*}{$\begin{array}{c}\text { Adolescent } \\
\text { Involvement }\end{array}$} & \multicolumn{2}{|c|}{ Parent-child Communication } & \multicolumn{2}{|c|}{ Knowledge/ Awareness } & \multicolumn{2}{|c|}{ Parental Monitoring } & \multicolumn{2}{|c|}{ Parental Modelling } \\
\hline & & & & $\begin{array}{l}\text { Prevention } \\
\text { Postcards }\end{array}$ & $\begin{array}{c}\text { Social Trivia } \\
\text { Night }\end{array}$ & Open Forum & $\begin{array}{c}\text { Audio- } \\
\text { visual Quiz }\end{array}$ & $\begin{array}{c}\text { Effective } \\
\text { Monitoring } \\
\text { Strategies }\end{array}$ & $\begin{array}{l}\text { Teen Party } \\
\text { Simulation }\end{array}$ & $\begin{array}{l}\text { Effective } \\
\text { Modelling } \\
\text { Strategies }\end{array}$ & $\begin{array}{c}\text { The Cool } \\
\text { Parent }\end{array}$ \\
\hline Come Home Safe & $\begin{array}{c}\text { Open forum, } \\
\text { online, } \\
\text { postal }\end{array}$ & Annually & Yes & - & & - & - & & - & & \\
\hline Open Forum & $\begin{array}{c}\text { Open forum, } \\
\text { online }\end{array}$ & 1 - 2 Hours & No & & & $\bullet$ & & - & & & \\
\hline Think Tank & $\begin{array}{c}\text { Open } \\
\text { foprum, } \\
\text { online, } \\
\text { postal }\end{array}$ & $\begin{array}{c}\text { Half hour a } \\
\text { week for } 8 \\
\text { weeks }\end{array}$ & Yes & $\bullet$ & & • & $\bullet$ & - & • & & \\
\hline P4 & $\begin{array}{c}\text { Open forum, } \\
\text { online }\end{array}$ & 1 Hour & Yes & & & - & & & $\bullet$ & & \\
\hline Parenteening & $\begin{array}{c}\text { Open forum, } \\
\text { online, } \\
\text { postal }\end{array}$ & Annually & No & $\bullet$ & & - & & & - & & \\
\hline Story Telling & $\begin{array}{c}\begin{array}{c}\text { YouTube, } \\
\text { books, TV }\end{array} \\
\end{array}$ & $\mathrm{n} / \mathrm{a}$ & Yes & & & & & & & & \\
\hline Alcohol Awarenes & $\begin{array}{c}\text { Workshop } \\
\text { (open forum) }\end{array}$ & Full day & Yes & & & $\bullet$ & & $\bullet$ & $\bullet$ & & \\
\hline Total ac & tivity used in & program des & & 3 & $\mathbf{0}$ & 6 & 2 & 3 & 5 & $\mathbf{0}$ & $\mathbf{0}$ \\
\hline
\end{tabular}


Table 5: Key considerations for applying co-design to TSR

\begin{tabular}{|c|c|c|}
\hline Process stage & Description & Key considerations \\
\hline 1. Resourcing & $\begin{array}{l}\text { Relevant input for co-design sessions } \\
\text { to be sourced by researchers and/or } \\
\text { experts }\end{array}$ & $\begin{array}{l}\text { - The identification of relevant themes and activities from existing programs to inform the } \\
\text { development of the co-design tools. } \\
\text { - The development of an in depth understanding of the issues/problems related to the } \\
\text { underlying topic. }\end{array}$ \\
\hline 2. Planning & $\begin{array}{l}\text { Closely collaborate with key } \\
\text { stakeholders. Plan the following four } \\
\text { stages, including scenarios of } \\
\text { unexpected events that may arise } \\
\text { during the facilitation stage. }\end{array}$ & $\begin{array}{l}\text { - Regular meetings with the research team to plan the recruitment, sensitization and } \\
\text { facilitation stages. } \\
\text { - Networking the co-design session and underlying topic to create awareness among } \\
\text { stakeholders and the targeted user groups. }\end{array}$ \\
\hline 3. Recruiting & $\begin{array}{l}\text { Identify suitable users who are willing } \\
\text { to, and capable of, contributing to new } \\
\text { ideas that are appealing to the broader } \\
\text { user base. }\end{array}$ & $\begin{array}{l}\text { - Tap strong networks between 1) target users and relevant stakeholders, and 2) project } \\
\text { team and relevant stakeholders to identify and recruit potential participants. } \\
\text { - Incentivise user communities by making them aware of the contribution they can make } \\
\text { through their participation. }\end{array}$ \\
\hline 4. Sensitising & $\begin{array}{l}\text { Make participants familiar with the } \\
\text { underlying topic by allowing them to } \\
\text { experience and test existing activities. }\end{array}$ & $\begin{array}{l}\text { Integrate sensitising techniques into the co-design session in cases where user groups are } \\
\text { time poor or not accessible. Allow participants to 'break free' from their everyday life to } \\
\text { help them to become aware of the specific roles they play and the changes they can make. }\end{array}$ \\
\hline 5. Facilitation & $\begin{array}{l}\text { Ice-breaker activities and design tools } \\
\text { assist in developing trust, empowering } \\
\text { participants and fostering creativity } \\
\text { and collaboration among team } \\
\text { members. }\end{array}$ & $\begin{array}{l}\text { - Using tools to reduce the dominance of the facilitator, but at the same time, avoid off- } \\
\text { topic discussions. Finding the fine line between close guidance (to ensure progress and } \\
\text { outcomes that align with the set targets) and giving voice to the users (to empower users to } \\
\text { contribute their unique knowledge and skills). } \\
\text { - Conclude the session with short idea presentation from each group to ensure that the } \\
\text { content and purpose of the generated ideas are fully understood, to recognize everyone's } \\
\text { contribution, and develop a sense of accomplishment. }\end{array}$ \\
\hline 6. Evaluation & $\begin{array}{l}\text { Develop clear recommendations for } \\
\text { program design, carefully gauging } \\
\text { feasibility }\end{array}$ & $\begin{array}{l}\text { - Analysing the gathered data with specific focus on (latent) user needs, user experiences, } \\
\text { and specific program preferences. The insights set the starting point for new value } \\
\text { propositions that more effectively support users in their value creation processes. }\end{array}$ \\
\hline
\end{tabular}


Table 6: Users' contributions and resulting changes to the existing education programs

\begin{tabular}{ll} 
Innovation & Description \\
\hline Change of user & Changes in the users' roles (i.e., \\
parents, educator, adolescents) in \\
terms of access, time commitment, \\
and learning experience.
\end{tabular}

Changes in the value proposition (parent alcohol education program)

Changing the way users access the program: Parents have the flexibility when and how to access the program. They still have the opportunity to attend a brief face-to-face session, however, the program material is made available through multiple platforms, such as via mail or online.

Changing the time commitment required of users: The successful completion of the program does not require parents to commit to multiple and lengthy sessions. Instead, parents have the flexibility to complete the program in their own pace and time.

Changing the learning experience of the program: Rather than focusing on dyadic face-to-face deliveries where parents act as passive listeners, multiple learning platforms are provided that enable parents to interact with experts, other parents, or involve their children.

\begin{tabular}{lll}
\hline $\begin{array}{l}\text { Change of } \\
\text { organisation's } \\
\text { value creation }\end{array}$ & $\begin{array}{l}\text { Changes in the transfer of operant } \\
\text { resources }\end{array}$ & $\begin{array}{l}\text { Exploring new ways to support parents' value creation processes by testing different delivery } \\
\text { platforms that facilitate a more tailored approach to the users' specific preferences and lifestyle. }\end{array}$ \\
$\begin{array}{l}\text { Changing the integrators of } \\
\text { resources }\end{array}$ & $\begin{array}{l}\text { Developing new learning interfaces (i.e., online learning platforms, mobile phone applications) and } \\
\text { utilizing new providers (e.g., YouTube) that let parents' to play a more active and flexible role as } \\
\text { resource integrator during the value creation process. }\end{array}$
\end{tabular}

Changes in the value constellation Redefining the way how the service is delivered by bringing together different actors (e.g., parents, experts, adolescents, policy makers) and allow them to interact, exchange knowledge, and collaboratively tackle the issue at hand. 